\title{
Ammonia Volatilization from Direct Seeded Later-rice Fields as Affected by Irrigation and Nitrogen Managements
}

\author{
Linxian Liao ${ }^{1}$, Xiaohou Shao ${ }^{1}$, Renjing $\mathrm{Ji}^{1}$, Tao Wen ${ }^{1}$ and Junzeng $\mathrm{Xu}^{1,2^{*}}$ \\ ${ }^{1}$ College of water conservancy and hydropower engineering, Hohai University, Nanjing, 210098, China \\ ${ }^{2}$ State key laboratory of hydrology-water resources and hydraulic engineering, Hohai University, Nanjing, 210098, China \\ *For correspondence: xjz481@hhu.edu.cn
}

\begin{abstract}
Ammonia volatilization (AV) from direct seeded later-rice (DSR) fields was investigated based on plot experiment with different irrigation (traditional flooding irrigation (TI) and controlled irrigation (CI)) and nitrogen (farmers' fertilization practice (FF) and controlled released urea (CU)) managements. Seasonal AV losses were 64.0, 69.5, 33.0 and 24.6 kg N ha ${ }^{-1}$ from CIFF, TIFF, TICU and CICU fields, accounting for 18.3, 19.9, 13.7 and 10.3\% of nitrogen inputs not as high as expected, and falling in the range reported in transplanted rice fields with the similar nitrogen treatments. Thus, it is difficult to answer the question if DSR practice will lead to significantly higher AV loss than transplanted cultivation. Mixed basal nitrogen fertilizer into muddy and frequently rainfall in the first forty days in rice season might account for the low AV loss percentages from DSR field in current research. Both nitrogen and irrigation management significantly affected AV loss from DSR fields, with the nitrogen management as the predominant factor. Compared with the farmers' fertilization, controlled released urea led to the reduced and retarded AV process. The controlled irrigation led to higher AV peaks immediately after nitrogen application in short period, but lower AV rates in long periods after the pulse AV emission than traditional flooding irrigation. The combination of controlled irrigation and controlled released urea is help to reduce AV loss from DSR field. C 2015 Friends Science Publishers
\end{abstract}

Keywords: direct seeded rice; Ammonia volatilization; Controlled released urea; Controlled irrigation

\section{Introduction}

Ammonia volatilization (AV) is one of the most important pathways of nitrogen $(\mathrm{N})$ loss from rice fields, which accounted for about $10 \%-60 \%$ of nitrogen application (Fillery and De Datta, 1986; Xu et al., 2012). Large amounts of ammonia emitted into the atmosphere exerted toxic, eutrophic and acidifying effects on ecosystem (Van der Eerden et al., 1998; Emmett, 2007; Pinder et al., 2007; Liu and Diamond, 2008).

Many researches addressed on the AV loss from transplanted rice fields with different nitrogen management, including types, amount and application methods of nitrogen fertilizers. Controlled released urea (CU), deep fertilization, and urease inhibitors were always considered as important methods to reduce AV loss from rice fields (Zhu et al., 1989; Wang et al., 2007; Li et al., 2008b; Hayashi et al., 2008; Pacholski et al., 2008; Sanz-Cobena et al., 2008; Scivittaro et al., 2010; Xu et al., 2012). Meanwhile, water-saving irrigation, which was widely adopted in rice cultivation to cope with water scarcity (Mao, 2001; Bouman et al., 2007), led to change of nitrogen losses and nitrogen balance in rice fields. The influence of water management or combined water and nitrogen managements on AV loss from rice paddies arose as a new issue recently (Li et al., 2008a; Xu et al., 2012). Scivittaro et al. (2010) indicated that moist soil resulted in higher AV losses than muddy soil. Li et al. (2008a) and Xu et al. (2012) found the first flooding - drying cycle after $\mathrm{N}$ fertilization led to higher AV loss in the short period than flooding irrigation, but multi wet-dry cycles are likely to reduce the seasonal AV loss from transplanted rice fields, and concluded that a higher water level during the first flooding - drying cycle period after surface fertilizer application was necessary to mitigate AV loss from the zero-drainaged or non-flooding irrigated rice fields. Furthermore, the combination non-flooding irrigation and controlled released urea was effective to reduce AV loss from transplanted rice fields $(\mathrm{Xu}$ et al., 2012). Thus, nitrogen and water managements are important practices linked with AV loss from the traditional transplanted rice fields.

With the rural economic development and agricultural restructuring in developing countries, direct seeded rice (DSR) cultivation has been established and adopted as a substitute for transplanted rice due to the advantage of labor-saving (Bhushan et al., 2007; Gangwar et al., 2008; 
Farooq et al., 2011). When transplanted rice cultivation was replaced by DSR, the nitrogen losses by $\mathrm{AV}$, surface runoff and leaching, and nitrogen uptakes of crop would change definitely, that put forward a request of appropriate management for nutrient and irrigation (Farooq et al., 2009, 2011). Regarding AV loss, most of the mentioned researches were conducted in traditional transplanted rice fields, with only few results from DSR fields. Watanbe et al. (2009) found AV loss $(17.7 \%$, in Can Tho) was higher from DSR fields than from conventional transplanted rice fields (5.5-17.4\%, in Bac Giang and Hanoi). Zhang et al. (2011) found non-tillage practice used in DSR fields resulted in higher AV loss than from conventional tillage rice fields. A pot experiment focusing on the AV loss from DSR fields in gemmiparous and early seedling stages indicated that monthly AV loss from rice fields with different nitrogen managements accounted for 27.6-59.7\% of nitrogen inputs, which was much higher than AV loss from conventional transplanted rice fields with the similar nitrogen managements. The absence of crop uptake and canopy roof, the very shallow water conditions in DSR fields favored the $\mathrm{AV}$ process during gemmiparous and seedling stages (Xu et $a l ., 2013)$. Thus, the DSR practice, which was preferred by farmers due to the advantage of labor-saving, might favor the AV process from flooding rice paddies. But detail information about seasonal AV process from DSR fields as affected by practice of irrigation and nitrogen managements is still unknown, which is essential for appropriate water and nutrient management in DSR fields.

In current research, field experiment was conducted aiming to reveal the influence of combined water and nitrogen managements on AV loss from DSR fields.

\section{Materials and Methods}

\section{Site Description}

Plot experiment was conducted in 2011 at Nanjing Vegetables Scientific Research Institute $\left(31^{\circ} 56^{\prime} \mathrm{N}\right.$, $\left.118^{\circ} 37^{\prime} \mathrm{E}\right)$, Jiangsu, China. This region has a subtropical monsoon climate, with average annual air temperature of $15.6^{\circ} \mathrm{C}$ and mean annual precipitation of $1,107 \mathrm{~mm}$. The soil in the top $20 \mathrm{~cm}$ was water loggogenic paddy soil (Gong, 1999), with the texture of silty clay loam. Total nitrogen, total phosphorus and organic matter contents were $1.51,0.21$ and $13.2 \mathrm{~g} \mathrm{~kg}^{-1}$, respectively, and soil $\mathrm{pH}$ was 6.85 .

\section{Experiment Design}

There were two irrigation treatments (traditional flooding irrigation TI and non-flooding controlled irrigation CI) and two fertilization treatments (farmers' fertilization practice FF and CU) in the experiment. The experiment, with all four treatments (TIFF, CIFF, TICU and CICU), was laid out in 12 plots $(2 \mathrm{~m} \times 5 \mathrm{~m})$ in a randomized complete block design
(RCBD) two factorial arrangement with three replications. In flooding irrigation fields, 30-50 mm standing water (up to $10 \mathrm{~mm}$ in gemmiparous and early seedling stage) was maintained except in later tillering and yellow maturity period. For the controlled irrigation treatment, flooding water (up to $50 \mathrm{~mm}$ for less than 5 days) was maintained in rice fields only during the period for fertilization, pesticide applications and rainfall harvesting, otherwise irrigation was applied only to keep soil moist. The lower and upper thresholds of soil moisture for controlled irrigation were $80 \%$ of saturated soil moisture and $10 \mathrm{~mm}$ ponding water in gemmiparous and seedling stage, and in other stages were the same to the thresholds reported by $\mathrm{Xu}$ et al. (2012) in transplanted rice. Fertilization records in both fertilization treatments were listed in Table 1. The basal fertilizer was mixed into the muddy to a depth about $10 \mathrm{~cm}$, and the additional fertilizers were dissolved in the water and poured into the plots evenly during irrigation. The controlled released urea used in current research was sulfur-coated urea, in which nitrogen content is $42 \%$, provided by Kingenta Ecological Engineering Group Co., Ltd., China. Rice seeds (variety of Nanjing 42, pre-germinated with dry-raised nurse seed coat for $24 \mathrm{~h}$ ) were broadcast evenly onto the paddy soil surface in dosage of $40 \mathrm{~kg}$ dry seeds ha ${ }^{-1}$ on July 4 , 2011.

\section{Sampling and Measurements}

Samples for AV rates measurement were collected via the polyvinyl chloride polymer ventilation collectors (height $=$ $20 \mathrm{~cm}$, diameter $=14 \mathrm{~cm}$ ), with a phosphoglycerol-soaked sponge inside as the absorbent (Wang et al., 2004). After each nitrogen fertilization, samples were collected daily at 10:00 am for the first 5 days, and then at 3-5 days interval. The phosphoglycerol soaked sponges taken out from the collectors were immediately immersed into $300 \mathrm{~mL}$ of 1.0 mol L ${ }^{-1} \mathrm{KCl}$ solution in $500 \mathrm{~mL}$ containers. Then, the containers were sealed and shaken for one hour on a reciprocating shaker. The ammonia nitrogen concentrations in the extracted solutions were analyzed using an ultraviolet-visible spectrophotometer (Rayleight UV1800), and the AV rate was calculated using Equation 1:

$$
\mathrm{R}_{\mathrm{AV}}=\frac{\mathrm{M}}{\mathrm{A} \cdot \mathrm{D}} \times 10^{-2}
$$

Where, $R_{\mathrm{AV}}$ is the AV rate (in $\mathrm{kg} \mathrm{N}$ ha $^{-1} \mathrm{~d}^{-1}$ ), $M$ is the amount of ammonia nitrogen in the extracted solution or in the sponge (in $\mathrm{mg} \mathrm{N}$ ), $A$ is the cross-sectional area of the ventilation collector (in $\mathrm{m}^{2}$ ), and $D$ is the sampling interval (in days).

Soil moisture and water layer were measured by using WET soil moisture sensor (Delta-T, UK) and vertical rulers fixed in the plots, to determine the time for irrigation. Daily meteorological data, including sunshine hours, minimum, maximum temperature, wind velocity and rainfall, were recorded using an automatic weather station (Fig. 1). 

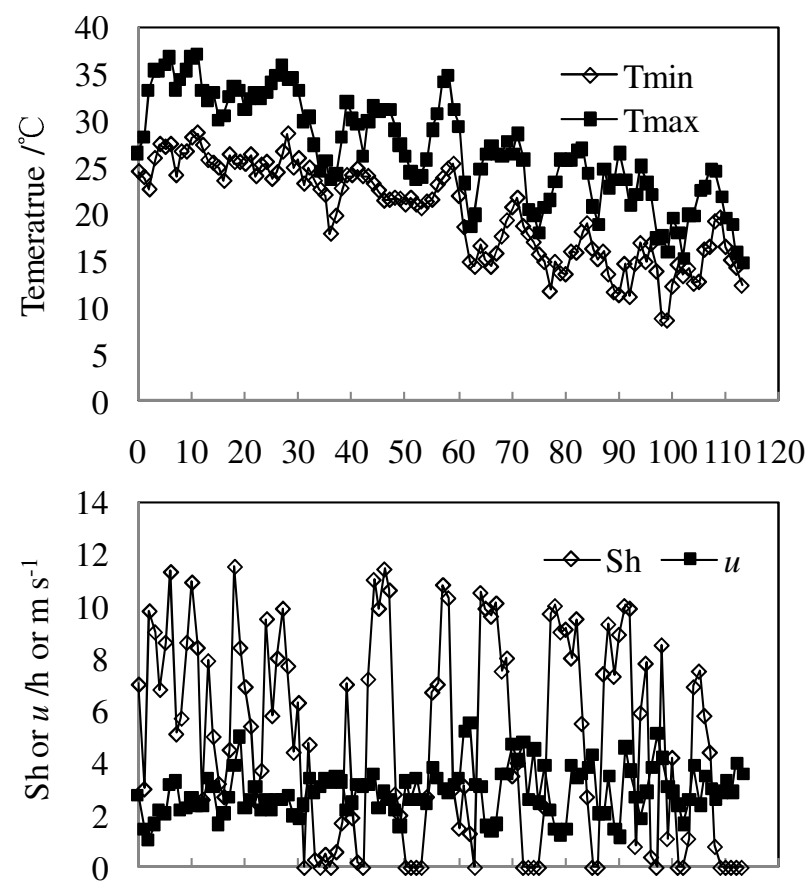

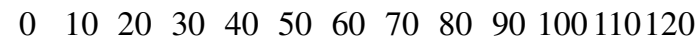

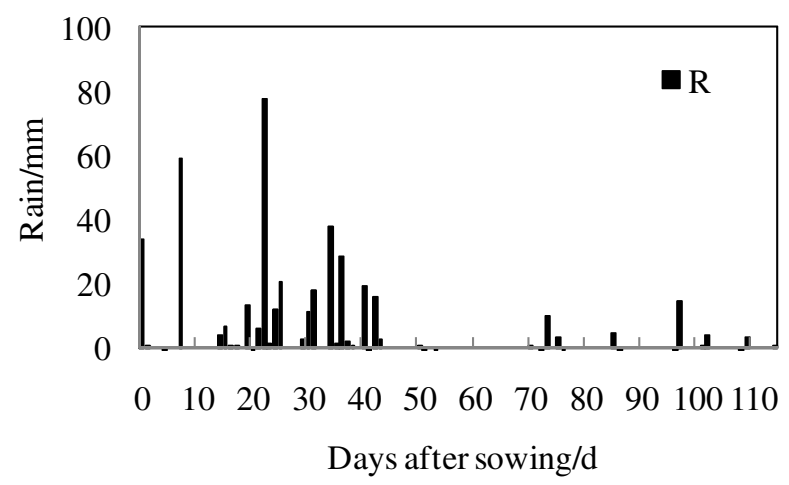

Fig. 1: Weather conditions of daily minimum temperature $\left(\mathrm{T}_{\min }\right)$, maximum temperature $\left(\mathrm{T}_{\max }\right)$, sunshine hours $\left(\mathrm{S}_{\mathrm{h}}\right)$, wind velocity $(u)$ and rainfall $(\mathrm{R})$

Surface water samples were collected from rice fields and stored in $250 \mathrm{~mL}$ glass conical flasks, and ammonium nitrogen contents in the surface water was determined.

\section{Statistically Analysis}

Multiple comparisons for AV loss from DSR fields were determined by Tamhane's tests at 0.05 probability level. Correlation coefficients were calculated to reveal the relations between $\mathrm{AV}$ rates and meteorological variables. Analysis of variance (MANOVA, multivariate analysis of variance) was used to measure the impact of nitrogen and water management on AV rates through calculation of the mean differences. The statistical analysis was performed using SPSS software for Windows (SPSS 13.0, Inc., Chicago, IL).

\section{Results}

\section{Ammonia Volatilization Rates}

AV processes from DSR rice fields were almost the same between treatments with the same nitrogen management (Fig. 2). In CIFF and TIFF treatments, there were three pulse AV fluxes lasting about one week immediately after each nitrogen application. Peak AV rates were 8.69 and 8.57 $\mathrm{kg} \mathrm{N} \mathrm{ha}{ }^{-1} \mathrm{~d}^{-1}$ immediately after the basal fertilizer in TIFF and CIFF treatments, then decreased to 0.56 and $0.96 \mathrm{~kg} \mathrm{~N}$ $\mathrm{ha}^{-1} \mathrm{~d}^{-1}$ in one week. The peaks after tillering fertilizer were 13.0 and $9.7 \mathrm{~kg} \mathrm{~N} \mathrm{ha}^{-1} \mathrm{~d}^{-1}$ in CIFF and TIFF paddies, which were the maximum in the whole season, then reduced to less than $1 \mathrm{~kg} \mathrm{~N} \mathrm{ha}^{-1} \mathrm{~d}^{-1}$ within one week after nitrogen fertilization. The nitrogen application rate for basal fertilizer was $198 \mathrm{~kg} \mathrm{~N} \mathrm{ha}^{-1}$, much higher than the rate for tillering and panicle fertilizer $\left(66 \mathrm{~kg} \mathrm{~N} \mathrm{ha}^{-1}\right)$, but the $\mathrm{AV}$ rates were higher following the tillering fertilizer than basal fertilizer. It implied that the AV process was reduced by incorporating nitrogen into soil. The nitrogen dosage were the same for tillering and panicle fertilizer, but $\mathrm{AV}$ rates after panicle fertilizer (2.13 and $1.74 \mathrm{~kg} \mathrm{~N} \mathrm{ha}^{-1} \mathrm{~d}^{-1}$ in CIFF and TIFF paddies) were much lower, due to poor ventilating condition under high canopy shelter and low air temperature. For TICU and CICU treatments, there were much lower peaks of AV (3.03 and $2.63 \mathrm{~kg} \mathrm{~N} \mathrm{ha}^{-1} \mathrm{~d}^{-1}$ ) than in TIFF and CIFF treatments. But during the non-pulse emission period, the AV rates were higher from TICU and CICU treatments than the TIFF and CIFF. It indicated that nitrogen management is the dominate factor in regulating the AV process from DSR rice fields, and controlled released urea led to reduced and retarded AV process.

Compared with the traditional flooding irrigation, non-flooding controlled irrigation led to slight change in AV process. Controlled irrigation always led to higher AV peaks after nitrogen application in short period, but lower AV rates in non-pulse emission periods. Peak AV rates after tillering and panicle fertilizers were 13.0 and $3.03 \mathrm{~kg} \mathrm{~N} \mathrm{ha}^{-1} \mathrm{~d}^{-1}$ in CIFF and CICU treatments, higher than the peaks in TIFF and TICU treatments (9.7 and $2.63 \mathrm{~kg} \mathrm{~N} \mathrm{ha}^{-1} \mathrm{~d}^{-1}$ ).

\section{Seasonal Ammonia Volatilization}

The seasonal AV losses were calculated as 64.0, 69.5, 33.0 and $24.6 \mathrm{~kg} \mathrm{~N} \mathrm{ha}^{-1}$ from DSR fields with CIFF, TIFF, TICU and CICU treatments, respectively (Table 2), accounting for $18.3,19.9,13.7$ and $10.3 \%$ of seasonal nitrogen inputs. Fig. 2 also indicated the pulse emissions lasting for about one week immediately after nitrogen application in FF nitrogen treatment. Weekly AV losses immediately after nitrogen application from DSR fields were 55.4, 52.7, 9.1 and $7.2 \mathrm{~kg}$ $\mathrm{N}$ ha $^{-1}$ for CIFF, TIFF, TICU and CICU treatments, respectively (Table 2), accounting for 86.5, 75.8, 27.6 and $29.4 \%$ of seasonal cumulative AV losses from rice fields. One month AV losses after basal application in TICU and CICU treatments were 21.2 and $17.8 \mathrm{~kg} \mathrm{~N} \mathrm{ha}^{-1}$, accounting 

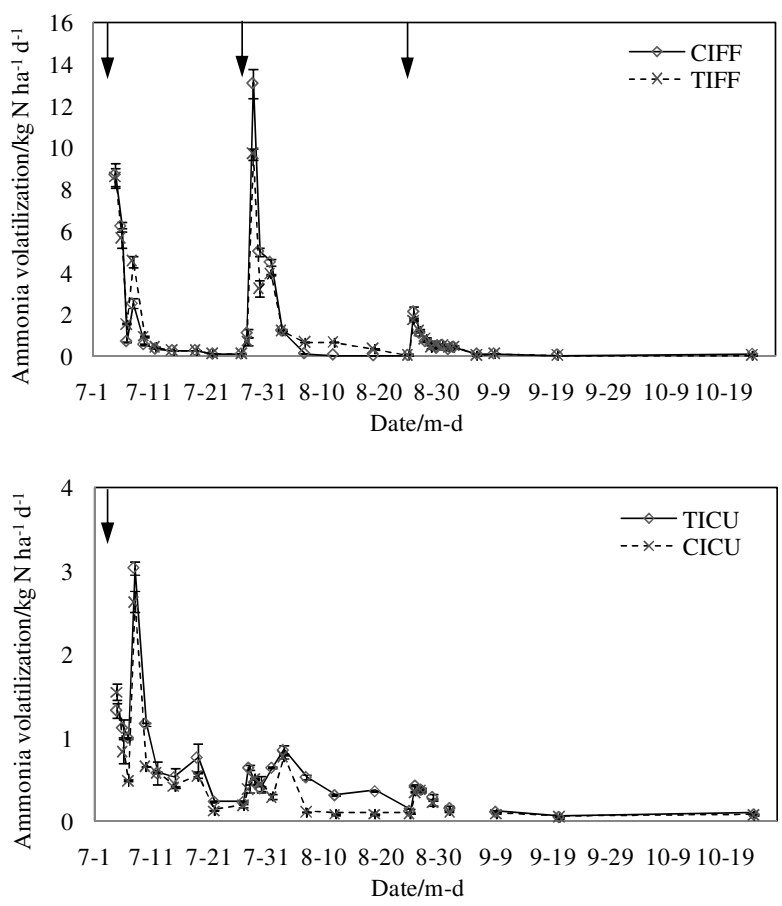

Fig. 2: Ammonia volatilization flux from direct seeded rice field with different irrigation and nitrogen managements (arrows indicated the nitrogen application, error bars error bars indicate the standard deviation)
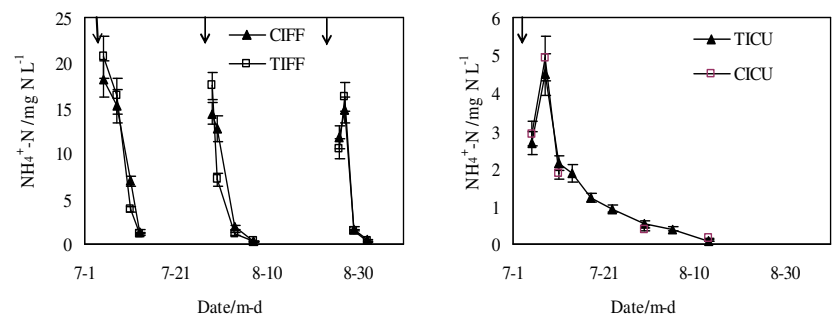

Fig. 3: Ammonium nitrogen contents in surface water of DSR fields following nitrogen application (arrows indicated the nitrogen application, error bars error bars indicate the standard deviation)

for 64.3 and $72.2 \%$ of seasonal AV losses. It confirmed again that controlled released urea resulted in much reduced and retarded AV process than farmers' fertilization treatment. Non-flooding controlled irrigation might lead to more AV loss than traditional flooding irrigation during pulse emission period, but a slight less AV loss totally in the whole rice season.

\section{Discussion}

A few studies reported that DSR resulted in higher AV loss than transplanted rice cultivation. Watanabe et al. (2009) found AV losses from DSR fields (17.7\%, in Can Tho) was higher than those from traditional transplanted rice fields
(5.5-17.4\%, in Bac Giang and Hanoi). AV losses from non-tillage DSR fields were reported as 27.6 and $36.7 \mathrm{~kg} \mathrm{~N}$ $\mathrm{ha}^{-1}$ in 2009 and 2010 in central China, accounting for 13.2 and $17.5 \%$ of seasonal nitrogen inputs (Zhang et al., 2011). A pot experiment carried focusing on the AV loss from DSR rice pots in gemmiparous and early seedling stages indicated that monthly AV loss from DSR rice fields might as high as $45.1 \%, 30.6 \%$ and $27.6 \%$ of nitrogen inputs for $5 \mathrm{~cm}$ deep application of ammonium bicarbonate, urea and controlled released urea. Those AV rates were much higher than the results from transplanted rice field, partially due to the influence of DSR practice $(\mathrm{Xu}$ et al., 2013). In current experiment, the percentages of AV loss to nitrogen inputs were almost the same to the results from DSR field by Watanabe et al. (2009) and Zhang et al. (2011), but much lower than the result by Xu et al. (2013) from a DSR pot. The low AV rates in current experiment might be ascribed to the practice of mixing large amount of the basal nitrogen fertilizer (account for $60 \%$ and $100 \%$ of seasonal nitrogen inputs in farmers' fertilization and controlled released urea treatments) into muddy, and the frequently rainfall in the first forth days (as in Fig. 1). Thus, the AV loss from DSR fields in current research was not as high as expected.

In current research, seasonal AV loss from the DSR fields with farmers' fertilization treatment was 64.0-69.5 $\mathrm{kg} \mathrm{N} \mathrm{ha}{ }^{-1}$, accounting for 18.3-19.9\% of season nitrogen inputs $\left(300 \mathrm{~kg} \mathrm{~N} \mathrm{ha}^{-1}\right)$. Compared with the results with similar nitrogen inputs in transplanted rice fields, it was higher than the results of $11.3 \%$ in Shenyang (Chen et al., 2007), 11.7\% in Chonnam (Lim et al., 2009), $11.2-12.9 \%$ in Jiaxing (Li et al., 2008a), 13.6-14.3\% in Changsu (Li et al., 2008a), but lower than the results of $34.7 \%$ in Changsu (Li et al., 2008b), 25\% in Wuxi (Xue et al., 2011), 25.9-36.5\% in Changsu (Wang et al., 2007), and 31.1-36.1\% in Kunshan (Xu et al., 2012). For controlled released urea treatments, the AV loss from the DSR fields in current research was $24.6-33.0 \mathrm{~kg} \mathrm{~N}^{-1}$, accounting for $10.3-13.7 \%$ of season nitrogen inputs (240 kg N ha $\left.{ }^{-1}\right)$. These percentages fell in the range of $\mathrm{AV}$ rates reported in transplanted rice field with the same nitrogen management. The percentage of AV loss to nitrogen inputs was reported as $8.0 \%$ in Wuxue (Cao et al., 2010), 0.5\% in Yingtan (Wang et al., 2011), 1.1-5.6\% in Changsu (Wang et al., 2007; Li et al., 2008b), 13\% in Wuxi (Xue et al., 2011), and 13.2-18.5\% in Kunshan (Xu et al., 2012). In current research, the AV loss percentage in the DSR fields fell in the ranges reported in transplanted rice fields with the similar nitrogen treatments. Thus, it is difficult to answer if DSR practice will lead to significantly higher AV loss than transplanted cultivation.

The degree of AV loss differs with types, dosages and application methods of nitrogen fertilizers (Wang et al., 2007; Hayashi et al., 2008; Xu et al., 2012). Pulse AV immediately after nitrogen application (Fig. 2) confirmed 
Table 1: Fertilization records for different treatments

\begin{tabular}{|c|c|c|c|}
\hline Treatments $^{\dagger}$ & Basal fertilizer, July $4\left(\mathrm{~kg} \mathrm{~N} \mathrm{ha}^{-1}\right)$ & $\begin{array}{l}\text { Tillering fertilizer, July } 2 \\
\left(\mathrm{~kg} \mathrm{~N} \mathrm{ha}^{-1}\right)\end{array}$ & $\begin{array}{l}6 \text { Panicle fertilizer, August } 24 \\
\left(\mathrm{~kg} \mathrm{~N} \mathrm{ha}^{-1}\right)\end{array}$ \\
\hline $\begin{array}{l}\text { TIFF, CIFF } \\
\text { TICU, CICU }\end{array}$ & $\begin{array}{l}198\left(\text { Compound fertilizer, } 660 \mathrm{~kg} \mathrm{ha}^{-1} ; \text { ammonium chloride, } 381 \mathrm{~kg}^{-1} \text { ha }\right. \\
240\left(\text { Control released urea, } 571 \mathrm{~kg} \mathrm{~h}^{-1}\right)\end{array}$ & $\begin{array}{lll}66 & (\text { Urea, } 143 \mathrm{~kg} & \left.\text { ha }^{-1}\right) \\
0 & & \end{array}$ & $\begin{array}{l}66\left(\text { Urea, } 143 \mathrm{~kg} \mathrm{ha}^{-1}\right) \\
0\end{array}$ \\
\hline
\end{tabular}

Table 2: Seasonal and weekly ammonia volatilization after nitrogen fertilization

\begin{tabular}{lllll}
\hline Treatments & \multicolumn{3}{c}{ Seasonal } & Weekly after N fertilization \\
\cline { 2 - 5 } & AV losses Kg ha ${ }^{-1}$ & Percents to N inputs \% & AV losses Kg ha ${ }^{-1}$ & Percents to seasonal losses \% $^{86.6}$ \\
\hline CIFF & $64.0 \mathrm{a}$ & 18.3 & $55.4 \mathrm{a}$ & 75.8 \\
TIFF & $69.5 \mathrm{a}$ & 19.9 & $52.7 \mathrm{a}$ & $27.6(64.3)^{\dagger}$ \\
TICU & $33.0 \mathrm{~b}$ & 13.7 & $9.1 \mathrm{~b}(21.2)^{\dagger}$ & $29.4(72.2)^{\dagger}$ \\
CICU & $24.6 \mathrm{c}$ & 10.3 & $7.2 \mathrm{~b}(17.7)^{\dagger}$ & \\
\hline
\end{tabular}

Means in the same volume followed by the same letter are not significantly different $(p<0.05)$ by Tamhane test

${ }^{\dagger}$ Figure in the bracket is monthly ammonia volatilization after control releases urea application and the percentages to seasonal ammonia volatilization

Table 3: MANOVA results for ammonia volatilization losses from DSR fields

\begin{tabular}{llll}
\hline Influence factor & SS & F & $p$ \\
\hline Nitrogen & 4294.6 & 3705.5 & $0.000^{* * * *}$ \\
Irrigation & 152.1 & 131.2 & $0.000^{* * *}$ \\
Interactive effect & 5.2 & 4.44 & 0.068 \\
Error & 9.2 & & \\
\hline$* * *$ indite & &
\end{tabular}

***indicate the correlation is significant at $\mathrm{p}<0.001$

Table 4: Correlations between ammonia volatilization and meteorological parameters

\begin{tabular}{|c|c|c|c|c|c|c|c|c|c|c|}
\hline \multirow[t]{2}{*}{ Treatment ${ }^{\dagger}$} & \multicolumn{5}{|c|}{ High AV rates period } & \multicolumn{5}{|c|}{ Low $\mathrm{AV}$ rates period } \\
\hline & Sh & Tmin & Tmax & $u$ & Tavg & Sh & Tmin & Tmax & $u$ & Tavg \\
\hline TIFF (n=13/18) & 0.416 & 0.250 & 0.026 & 0.084 & 0.113 & $0.445^{*}$ & $0.496^{*}$ & 0.385 & 0.234 & $0.485 *$ \\
\hline CIFF (n=13/18) & 0.334 & 0.208 & 0.017 & 0.187 & 0.086 & $0.460^{*}$ & 0.409 & $0.524 *$ & 0.265 & $0.484 *$ \\
\hline TICU (n=11/15) & 0.479 & 0.193 & 0.083 & 0.125 & 0.202 & 0.150 & $0.751^{*}$ & $0.533^{*}$ & 0.168 & $0.700 *$ \\
\hline $\operatorname{CICU}(\mathrm{n}=11 / 15)$ & 0.424 & 0.189 & 0.055 & 0.122 & 0.095 & 0.083 & $0.575^{*}$ & 0.467 & 0.127 & $0.570^{*}$ \\
\hline
\end{tabular}

*indicate the correlation is significant at $\mathrm{p}<0.05$

${ }^{\dagger}$ Numbers at left and right side of the slash are the number for high and low AV rates periods, separately

that nitrogen application is the dominant factor in regulating AV loss form DSR fields. The dosage of basal fertilizer in farmers' fertilization treatments was three times of nitrogen amount for tillering or panicle fertilizer. The absence of canopy shelter and crop uptakes following basal fertilizer were expected favored the AV process in DSR fields, but the peaks after basal fertilizer were not much higher than the peaks after tillering fertilizer. That might be ascribed to the basal fertilizer was mixed into soil, but the tillering fertilizer was broadcasted to surface water (Obcemea et al., 1988; Zhu et al., 1989; Hayashi et al., 2008). Controlled released urea in dosage of $240 \mathrm{~kg} \mathrm{~N} \mathrm{ha}^{-1}$ was mixed into soil all at once as basal fertilizer, higher than the basal fertilizer dosage in farmers' fertilization treatment. But the AV rates in DSR fields following controlled released urea application were much lower than the peaks in farmers' fertilization treatment following basal fertilizer. And the percentages of seasonal AV loss to nitrogen inputs in controlled released urea DSR fields were $10.3-13.7 \%$ of nitrogen inputs, also lower than the percentage in farmers' fertilization treatments (18.3-19.9\%). Controlled released urea always resulted in less AV loss form transplanted rice field(Wang et al., 2007; Li et al., 2008b; Cao et al., 2010; Wang et al., 2011; Xue et al., 2011), because the substrate concentration of AV was low due to the slowly release of urea. It was confirmed again in DSR fields. 
There are several reports on the influence of water management on AV loss from rice field. It was reported that high water level resulted in low AV losses from flooding transplanted rice fields (Li et al., 2008a). In current research, first wetting-drying cycle immediately after nitrogen application led to increased AV loss in short period, and multi wetting-drying cycles in controlled irrigation treatments resulted in reduced seasonal AV loss from DSR fields. Similar result was reported recently in transplanted rice fields (Xu et al., 2012).

MANOVA analysis indicated that both nitrogen and water management significantly affected AV losses from DSR fields (Table 3), and the former is the dominant factor. The mean variance for nitrogen management accounted for $96 \%$ of the sum of the squared deviation for AV losses from DSR field. The interactive effect between water and nitrogen managements on AV loss from DSR fields was not significant.

Ammonium nitrogen contents in surface water dominated the AV loss from transplanted rice fields (Jayaweera and Mikkelsen, 1991; Li et al., 2008a; Watanabe et al., 2009). It was confirmed it in DSR fields in current experiment. For farmers' fertilization treatments, ammonium nitrogen contents in surface soil were as high as 15-20 mg N L $\mathrm{m}^{-1}$ in 2-3 days after nitrogen application, and reduced to as low as $<1.0 \mathrm{mg} \mathrm{N} \mathrm{L}^{-1}$ in $7-9$ days after nitrogen application (Fig. 3). The period of pulse AV emission is consistent to the period when the ammonium nitrogen contents were high in surface water (Fig. 2 and 3). For controlled released urea treatments, ammonium nitrogen contents after nitrogen application were lower than in farmers' fertilization treatment. The ammonium nitrogen contents reduced gradually from the peaks about $4-5 \mathrm{mg} \mathrm{N}$ $\mathrm{L}^{-1}$ to $<1.0 \mathrm{mg} \mathrm{N} \mathrm{L}^{-1}$ in about 20 days (Fig. 3), during which the AV rates were relative high (Fig. 2).

Correlations between $\mathrm{AV}$ rates and meteorological variables were different between the period with high AV rates and the period with low AV rates (Table 4). For TIFF and CIFF treatments, correlations to metrological parameters during low AV rates periods were higher than the period with high AV rates. It indicated the ammonium nitrogen contents in surface water dominated the AV rates during the pulse emission period. For TICU and CICU treatments, it is the same except for the influence of sunshine hours. Comparison between irrigation treatments indicated that $\mathrm{AV}$ rates from controlled irrigation fields were less sensitive to meteorological variables than from traditional flooding irrigation fields. That may be ascribed to wetting-drying cycles in controlled irrigation fields bring more nitrogen into rizophere soils (Xu et al., 2012).

\section{Conclusion}

Seasonal AV loss was 64.0, 69.5, 33.0 and $24.6 \mathrm{~kg} \mathrm{~N}^{-1}$ from DSR field with CIFF, TIFF, TICU and CICU treatments, accounting for $18.3,19.9,13.7$ and $10.3 \%$ of seasonal nitrogen inputs. These percentages of AV loss to nitrogen inputs from DSR fields were not as high as expected, and fell in the range reported in transplanted rice fields with the similar nitrogen treatments. Thus, it is difficult to answer the question if DSR practice will lead to significantly higher AV loss than transplanted cultivation. Mixed basal nitrogen fertilizer into muddy and frequently rainfall in the first forty days of rice season might account for the low AV loss from DSR fields in current research. Both nitrogen and water management significantly affected AV loss from DSR fields, and nitrogen was the predominant factor. The combination of controlled irrigation and controlled released urea is help to reduce AV loss from DSR field.

\section{Acknowledgements}

The authors acknowledge funding from the Natural Science Foundation of Jiangsu Province (BK 2011742), and Advanced Science and Technology Innovation Team in Colleges and Universities in Jiangsu Province.

\section{References}

Bouman, B.A.M., R.M. Lampayan and T.P. Tuong, 2007. Water Management in Irrigated Rice: Coping with Water Scarcity. International Rice Research Institute, Los Baños, Philippines

Bhushan, L., J.K. Ladha, R.K. Gupta, S. Singh, A. Tirol-Padre, Y.S. Saharawat, M. Gathala and H. Pathak, 2007 Saving of water and labor in a rice-wheat system with no-tillage and direct seeding technologies. Agron. J., 99: 1288-1296

Cao, C.G., C.F. Li, Z.K. Kou, J.H. Yang and J.P. Wang, 2010. Effects of N source and tillage on $\mathrm{NH}_{3}$ volatilization from paddy soils. Acta Agric. Univ. Jiangxi, 32: 881-886

Chen, Z.H., L.J. Chen, Z.J. Wu, Y.L. Zhang and Y.H. Juan, 2007. Ammonia volatilization from rice field under different water conditions in lower Liaohe River Plain. Chin. J. Appl. Ecol., 18: 2771-2776

Emmett, B.A., 2007. Nitrogen saturation of terrestrial ecosystems: Some recent findings and their implications for our conceptual framework. Water Air Soil Poll., 7: 99-109

Farooq, M., N. Kobayashi, A. Wahid, O. Ito and S.M.A. Basra, 2009 Strategies for producing more rice with less water. Adv. Agron., 101: 351-388

Farooq, M., K.H.M. Siddique, H. Rehman, T. Aziz, D.J. Lee and A. Wahid, 2011. Rice direct seeding: Experiences, challenges and opportunities. Soil Till. Res., 111: 87-98

Fillery, I.R.P. and S.K. De Datta, 1986. Ammonia volatilization from nitrogen volatilization as a $\mathrm{N}$ loss mechanism in flooded rice fields. Fert. Res., 9: 78-98

Gangwar, K.S., O.K. Tomar and D.K. Pandey, 2008. Productivity and economics of transplanted and direct-seeded rice (Oryza sativa) based cropping systems in Indo-Gangetic plains. Ind. J. Agric. Sci., 78: 655-658

Gong, Z.T. 1999. Chinese Soil Taxonomy-theory, Methodology and Practice. Science Press, Beijing, China

Hayashi, K., S. Nishimura and K. Yagi, 2008. Ammonia volatilization from a paddy field following applications of urea: Rice plants are both an absorber and an emitter for atmospheric ammonia. Sci. Total Environ., 390: 485-494

Jayaweera, G.R. and D.S. Mikkelsen, 1991. Assessment of ammonia volatilization from flooded soil systems. In: Advances in Agronomy, Vol. 45, pp: 303-356. N.C. Brady (ed.). Academic Press, San Diego, USA 
Li, H., X.Q. Liang, Y.X. Chen, G.M. Tian and Z.J. Zhang, 2008a.Ammonia volatilization from urea in rice fields with zero-drainage water management. Agric. Water Manage., 95: 887-894

Li, H.L., Y. Han and Z.C. Cai, 2008b. Modeling the ammonia volatilization from common urea and controlled releasing urea fertilizers in paddy soil of Taihu region of China by Jayaweera Mikkelsen model. Environ. Sci., 29: 1045-1052

Lim, S.S., J.H. Kwak, D.S. Lee, S.I. Lee, H.J. Park, H.Y. Kim, H.S. Nam, K.M. Cho and W.J. Choi, 2009. Ammonia volatilization from rice paddy soils fertilized with ${ }^{15} \mathrm{~N}$-urea under elevated $\mathrm{CO}_{2}$ and temperature. Kor. J. Environ. Agric., 28: 233-237

Liu, J.G. and J. Diamond, 2008. Revolutionizing China's environmental protection. Science, 319: 37-38

Mao, Z., 2001. Water efficient irrigation and environmentally sustainable irrigated rice production in china. Available at: http://www.icid.org/wat_mao.pdf (Accessed: 06 October 2014)

Obcemea, W.N., J.G. Real and S.K. De Datta, 1988. Effect of soil texture and nitrogen management on ammonia volatilization and total nitrogen loss. Philipp. J. Crop Sci., 13: 145-153

Pacholski, A., G.X. Cai, X.H. Fan, H. Ding, D.L. Chen, R. Nieder and M. Roelcke, 2008. Comparison of different methods for the measurement of ammonia volatilization after urea application in Henan Province, China. J. Plant Nutr. Soil Sci., 171: 361-369

Pinder, R.W., P.J. Adams and S.N. Pandis, 2007. Ammonia emission controls as a cost-effective strategy for reducing atmospheric particulate matter in the Eastern United States. Environ. Sci. Technol., 41: 380-386

Sanz-Cobena, A., T.H. Misselbrook, A. Arce, J.I. Mingot, J.A. Diez and A. Vallejo, 2008. An inhibitor of urease activity effectively reduces ammonia emissions from soil treated with urea under Mediterranean conditions. Agric. Ecosyst. Environ., 126: 243-249

Scivittaro, W.B., D.R.N. Gonçalves, M.L. Campos do Vale and V.G Ricordi, 2010. Nitrogen losses by ammonia volatilization and lowland rice response to NBPT urease inhibitor-treated urea. Ciência Rural, 40: 1283-1289
Van der Eerden, L., W. de Vries and H. Van Dobben, 1998. Effects of ammonia deposition on forests in the Netherlands. Atmos. Environ., 32: 525-532

Wang, X.Z., J.G. Zhu, R. Gao, H. Yasukazu and K. Feng, 2007. Nitrogen cycling and losses under rice-wheat rotations with coated urea and urea in the Taihu Lake region. Pedosphere, 17: 62-69

Wang, X., J. Cui and J. Zhou, 2011. Ammonia volatilization of controlled-release urea enveloped with colophony from paddy field in typical red soil. Soils, 43: 56-59

Wang, Z.H., X.J. Liu, X.T. Ju, F.S. Zhang and S.S. Malhi, 2004. Ammonia volatilization loss from surface-broadcast urea: Comparison of vented-and closed-chamber methods and loss in winter wheat-summer maize rotation in North China Plain. Commun. Soil Sci. Plant Anal., 35: 2917-2939

Watanbe, T., T.T. Son, N.N. Hung, N.V. Troung, T.Q. Giau, K. Hayashi and O. Ito, 2009. Measurement of ammonia volatilization from flooded paddy fields in Vietnam. Soil Sci. Plant Nutr, 55: 793-799

Xu, J.Z., L.X. Liao, J.Y. Tan and X.H. Shao, 2013. Ammonia volatilization in gemmiparous and early seedling stages from direct seeding rice pots with different nitrogen management strategies. Soil Till. Res. 126: $169-176$

Xu, J.Z., S.Z. Peng, S.H. Yang and W.G. Wang, 2012. Ammonia volatilization losses from rice paddies with different irrigation and nitrogen managements. Agric. Water Manage., 104: 184-192

Xue, L.H., Y.L. Yu and L.Z. Yang, 2011. Nitrogen balance and environment impact of paddy field under different $\mathrm{N}$ management methods in Taihu Lake Region. Environ. Sci., 32: 1033-1038

Zhang, J.S., F.P. Zhang, J.H. Yang, J.P. Wang, M.L. Cai, C.F. Li and C.G Cao 2011. Emissions of $\mathrm{N}_{2} \mathrm{O}$ and $\mathrm{NH}_{3}$, and nitrogen leaching from direct seeded rice under different tillage practices in central China Agric. Ecosyst. Environ., 140: 164-173

Zhu, Z.L., J.R. Simpson, S.L. Zhang, G.X. Cai, D.L. Chen, J.R. Freney and V.A. Jackson, 1989. Investigations on nitrogen losses from fertilizers applied toflooded calcareous paddy soil. Acta Pedol. Sin., 26: 337-343

(Received 05 August 2014; Accepted 15 October 2014) 